\title{
Light deprivation: An efficient way in inducing depression- like behavior animal models
}

\author{
Chanyi Lu" ${ }^{1,2,5 \#}$, Hua-Zhen Lin ${ }^{3,4 \#}$, Yao-Yao Li ${ }^{1,2 *}$ and Yun-Feng Zhang ${ }^{1,2,6 *}$ \\ ${ }^{1}$ School of Ophthalmology \& Optometry, The Eye Hospital, Wenzhou Medical University, Wenzhou, Zhejiang, China \\ ${ }^{2}$ State Key Laboratory Cultivation Base and Key Laboratory of Vision Science, Ministry of Health P. R. China and Zhejiang Provincial Key Laboratory of \\ Ophthalmology and Optometry, China \\ ${ }^{3}$ The 2nd Affiliated Hospital and Yuying Children's Hospital, Wenzhou Medical University, Wenzhou, Zhejiang, China \\ ${ }^{4}$ The 2nd School of Medicine, Wenzhou Medical University, Wenzhou, Zhejiang, China \\ ${ }^{5}$ University of Pennsylvania School of Dental Medicine, Philadelphia, USA \\ ${ }^{6}$ Department of Neuroscience, University of Pennsylvania Perelman School of Medicine, Philadelphia, USA \\ \#Chanyi Lu, Hua-Zhen Lin and Yao-Yao Li contributed equally to this work.
}

\begin{abstract}
Depression as one kind of neuropsychiatric disorder leads to great burden to both the economy and society worldwide. A great number of animal models of depression emerge with an aim to unveil the underlying pathophysiological mechanism of this serious mental illness. Among of these animal models, depression-like behavior model induced by light deprivation is of great interest to us. However, the current state of knowledge concerning this kind of animal model of depression has been relatively few to date. In the current review, we concisely summarized some key historic and recent studies related to depressive-like phenotypes induced by light deprivation, and emphasized the importance of this efficient, convenient as well as inexpensive method in producing depression-like behavior animal models. Moreover, it was highlighted that light therapy when combined with some other antidepressant treatment was much more powerful and efficient. Last but not the least, much more efforts were also made to outline the possible mechanisms underlying how light deprivation producing the depressive-like phenotypes in animal models, in order to shed some light on the future studies on depression.
\end{abstract}

\section{Introduction}

Depression as one kind of life-threatening mental illness is prevalent and effects around $20 \%$ of the world's population [1]. Depression is considered as the fourth leading cause of disability, and is presumed to rank to the second place by 2020 [2]. A large body of depression-like behavior animal models emerged in order to decipher the pathophysiological mechanisms underlying this neuropsychiatric illness [3-11]. Details of some of these animal models of depression have been extensively documented by two recent reviews $[3,5]$. However, historic reviews pertaining to animal models of depression produced by light deprivation, to some extent, have been relatively few so far. In this short review, we briefly summarized the current state of knowledge regarding depression-like behavior animal models induced by light deprivation, and highlighted the relatively high efficiency of this method in producing depressive-like phenotypes. Also, a short glance at light therapy in depression and the potential mechanisms underlying light deprivation inducing depressive-like phenotypes were provided.

Light plays crucial roles during the occurrence of depressive-like phenotypes. It has been confirmed that either a chronic constant light $[12]$ or the light deprivation $[11,13,14]$ could well produce depressionlike behaviors in rodents. In addition, light was also effective in regulating mood and light deficiency could potentially result in depression. It was documented that the occurrence of depression was relatively higher in high latitudes where there was a limitation of light exposure [15]. A historic study showed that keeping rats in constant darkness for 6 weeks could produce obvious anatomical and behavioral features similar to depressed patients [11], which strengthens the potentially important association between the light and the occurrence of depression. Our recent study showed that light deprivation could successfully lead to a depression-like behavior mouse model [10]. In our study, mice treated with constant light deprivation for 3 weeks showed typical depressive-like phenotypes characterized by the significant increase in immobility time in both the forced swimming test and tail suspension test. Moreover, the anti-static fatigue test and exhaustive swimming test were carried out to investigate the effects of light deprivation on the locomotor activity of this depression-like behavior mouse model. Interestingly, it was confirmed that the duration of pole-climbing in the anti-static fatigue test and swimming time in the exhaustive swimming test were notably decreased in light deprivation mice, indicating that light deprivation weakens both the static and dynamic locomotor activity of the depressive-like mice. The decreased

Correspondence to: Yun-Feng Zhang, School of Ophthalmology \& Optometry, The Eye Hospital, Wenzhou Medical University, Wenzhou, Zhejiang, China; State Key Laboratory Cultivation Base and Key Laboratory of Vision Science, Ministry of Health P. R. China and Zhejiang Provincial Key Laboratory of Ophthalmology and Optometry, China; Department of Neuroscience, University of Pennsylvania Perelman School of Medicine, Philadelphia, PA, USA, Tel: (215) 746-2791; Fax: 215-573-9050; E-mail: zhangyunfeng1983@163.com; zhang18@ mail.med.upenn.edu

Received: August 02, 2017; Accepted: August 28, 2017; Published: August 30, 2017 
active behaviors of light deprivation mice revealed the stereotyped characteristics of depressive-like phenotypes, further highlighting the efficiency of light deprivation in inducing depression-like behavior animal models. Moreover, our another recent study confirmed that light deprivation not only could well produce a depressive-like phenotypes in mice but also result in sexual dimorphic effects on neural excitability and depression-like behaviors [9]. Collectively, all these evidence calls for making some room for the efficient role of light deprivation in producing depression-like behavior animal models.

On the other hand, nowadays bright light therapy has been considered as an efficient way in antidepressant treatment [16-21]. One recent study exploring the effectiveness of light therapy on college students who suffered form depression demonstrated that light therapy could successfully relieve depressive symptoms and remarkably increased improvements in overall depression scores [22]. Besides, light therapy could also ameliorate some other symptoms (bad sleeping behaviors, somatic aches and pains and concentration difficulties, as well as appetite problems) accompanied with depression. This promising study strongly suggests that light therapy may be an effective and inexpensive means for alleviating symptoms of young adult depression. In addition, it has been confirmed that light therapy for depression was much more powerful and efficient when combined with other antidepressant treatment methods [23,24], implying the meaningful perspectives of light therapy in the treatment of depression. In sum, as aforementioned above, light therapy is effective and convenient as well as inexpensive in successfully ameliorating depression symptoms, which in further underscores the importance of normal and enough light exposure in avoiding the occurrence of depression. Also, the effective role of light therapy, from the other side, is supportive for the feasibility and efficiency of light deprivation as a convenient way to induce depression-like behaviors in animal models.

Though a great number of studies have been focused on depressionlike behavior rodent models in order to unveil the mechanisms underlying the pathophysiology of depression [25-29], information concerning the mechanisms underlying light deprivation producing depression-like behaviors, however, is still limited to date. In the study by Gonzalez and Aston-Jones (2008), it was reported that light deprivation could lead to neural damage in monoamine brain systems, which, as they presumed, was associated with the depressive behavioral phenotypes in rats [11]. This suggests that prolonged limited light exposure may negatively affect mood and underlies the occurrence of depressive-like phenotypes in rats. Our recent study indicated that light deprivation could change motor cortical neural microcircuit, which may underlie the depression-like behaviors of mice [10]. It was confirmed that light deprivation decreased the proportion of burst firing layer 5 pyramidal cells in the motor cortex. Also, light deprivation suppressed the intrinsic electrophysiological properties of motor cortical layer 5 pyramidal cells. Moreover, light deprivation could lead to changes of the proportion of excitatory synaptic subtypes of layer 5 pyramidal cells. More interestingly, light deprivation decreased the synaptic connecting probability whereas increased the synaptic transmitter release probability and the absolute synaptic strength of excitatory synaptic connections formed by motor cortical layer 5 pyramidal cells. Our findings strongly support that light deprivation could well produce a depression-like behavior mouse model, and highlights the changes in motor cortical neural microcircuit induced by light deprivation being a potential mechanism underlying depression. The other possible underlying mechanism of light deprivation inducing depressive-like phenotypes is that light deprivation could change some inflammatory cytokines related to depression [30]. There are some evidence showing inflammatory cytokines playing some roles in depression [31-33], and some inflammatory cytokines were especially increased in patients with depression [34,35]. Thus, it could be reasonable that light deprivation as a stress may induce some great changes in the immune system, which, in the end, will lead to the increase or decrease of some key inflammatory cytokines closely associated with depression. Last but not the least, circadian changes resulted from light deprivation is another quite possible mechanism underlying the pathophysiology of depression, which was strongly supported by both historic studies $[11,15]$ and some recent research [36,37]. Though all these existing evidence, much more efforts are still needed to decipher the potential mechanisms underlying light deprivation inducing depression-like phenotypes in the future studies.

\section{Acknowledgements}

This study was supported by the grants from the Wenzhou Science and Technology Plans (No.Y20140139), the Foundation of School of Ophthalmology \& Optometry, The Eye Hospital, Wenzhou Medical University (YNCX201311), the Natural Science Foundation of Zhejiang Province of China (No. LQ14H120003) and the National Natural Science Foundation for Young Scientists of China (No. 81301117).

\section{References}

1. Stepanichev M, Dygalo NN, Grigoryan G, Shishkina GT, Gulyaeva N (2014) Rodent models of depression: neurotrophic and neuroinflammatory biomarkers. Biomed Res Int 2014: 932757. [Crossref]

2. Bromet E, Andrade LH, Hwang I, Sampson NA, Alonso J, et al. (2011) Cross-national epidemiology of DSM-IV major depressive episode. BMC Med 9: 90. [Crossref]

3. Kato T, Kasahara T, Kubota-Sakashita M, Kato TM, Nakajima K (2016) Animal models of recurrent or bipolar depression. Neuroscience 321: 189-196. [Crossref]

4. Hollis F, Kabbaj M (2014) Social defeat as an animal model for depression. ILAR J 55 221-232. [Crossref]

5. Wang Q, Timberlake MA 2nd, Prall K, Dwivedi Y (2017) The recent progress in animal models of depression. Prog Neuropsychopharmacol Biol Psychiatry 77: 99109. [Crossref]

6. Yurttas C, Schmitz C, Turgut M, Strekalova T, Steinbusch HWM (2017) The olfactory bulbectomized rat model is not an appropriate model for studying depression based on morphological/stereological studies of the hippocampus. Brain Res Bull 134: 128-135. [Crossref]

7. Morales-Medina JC, Iannitti T, Freeman A, Caldwell HK (2017) The olfactory bulbectomized rat as a model of depression: The hippocampal pathway. Behav Brain Res 317: 562-575. [Crossref]

8. McKinney WT Jr, Bunney WE Jr (1969) Animal model of depression. I. Review of evidence: implications for research. Arch Gen Psychiatry 21: 240-248. [Crossref]

9. Lu C, Wang Y, Zhang YF (2016) Light deprivation produces a sexual dimorphic effect on neural excitability and depression-like behavior in mice. Neurosci Lett 633: 69-76. [Crossref]

10. Zhang Y-F, Li Q-Q, Qu J, Sun C-M, Wang Y (2016) Alterations of motor cortical microcircuit in a depressive-like mouse model produced by light deprivation. Neuroscience 285: 139-154. [Crossref]

11. Gonzalez MM, Aston-Jones G (2008) Light deprivation damages monoamine neurons and produces a depressive behavioral phenotype in rats. Proc Natl Acad Sci US A 105 : 4898-4903. [Crossref]

12. Tapia-Osorio A, Salgado-Delgado R, Angeles-Castellanos M, Escobar C (2013) Disruption of circadian rhythms due to chronic constant light leads to depressive and anxiety-like behaviors in the rat. Behav Brain Res 252: 1-9. [Crossref]

13. Lau BW, Ren C, Yang J, Yan SW, Chang RC, et al. (2011) Light deprivation induces depression-like behavior and suppresses neurogenesis in diurnal mongolian gerbil (Meriones unguiculatus). Cell Transplant 20: 871-881. [Crossref]

14. Leach G, Adidharma W, Yan L (2013) Depression-like responses induced by daytime light deficiency in the diurnal grass rat (Arvicanthis niloticus). PLoS One 8: e57115. [Crossref] 
15. Monteleone P, Maj M (2008) The circadian basis of mood disorders: recent developments and treatment implications. Eur Neuropsychopharmacol 18: 701-711. [Crossref]

16. Rosenthal NE, Sack DA, Gillin JC, Lewy AJ, Goodwin FK, et al. (1984) Seasonal affective disorder. A description of the syndrome and preliminary findings with light therapy. Arch Gen Psychiatry 41: 72-80. [Crossref]

17. Mårtensson B, Pettersson A, Berglund L, Ekselius L (2015) Bright white light therapy in depression: A critical review of the evidence. J Affect Disord 182: 1-7. [Crossref]

18. Krysta K, Krzystanek M, Janas-Kozik M, Krupka-Matuszczyk I (2012) Bright light therapy in the treatment of childhood and adolescence depression, antepartum depression, and eating disorders. J Neural Transm (Vienna) 119: 1167-1172. [Crossref]

19. Kragh M, Møller DN, Wihlborg CS, Martiny K, Larsen ER, et al. (2017) Experiences of wake and light therapy in patients with depression: A qualitative study. Int J Ment Health Nurs 26: 170-180. [Crossref]

20. Kragh M, Martiny K, Videbech P, Møller D, Wihlborg C, et al. (2017) Wake and light therapy for moderate-to-severe depression-a randomized controlled trial. Acta Psychiatrica Scandinavica. [Crossref]

21. Sit D, McGowan J, Wiltrout C, Diler RS, Dills JJ, et al. (2017) 72-Light therapy for bipolar disorder: A randomized, double-blind, placebo-controlled trial of bright white versus dim red light for bipolar depression. Biological Psychiatry 81: S30.

22. House LA, Walton B (2017) The effectiveness of light therapy for college student depression. Journal of College Student Psychotherapy 1-11.

23. Penders TM, Stanciu CN, Schoemann AM, Ninan PT, et al. (2016) Bright light therapy as augmentation of pharmacotherapy for treatment of depression: A systematic review and meta-analysis. Prim Care Companion CNS Disord 18. [Crossref]

24. Combs G (2016) Light therapy helps depression regardless of season. Evidence-based practice $3: 4$

25. Seo JS, Zhong P, Liu A, Yan Z, Greengard P (2017) Elevation of p11 in lateral habenula mediates depression-like behavior. Mol Psychiatry. [Crossref]

26. Peña CJ, Kronman HG, Walker DM, Cates HM, Bagot RC, et al. (2017) Early life stress confers lifelong stress susceptibility in mice via ventral tegmental area OTX2. Science 356: 1185-1188. [Crossref]
27. Svenningsson P, Kim Y, Warner-Schmidt J, Oh YS, Greengard P (2013) p11 and its role in depression and therapeutic responses to antidepressants. Nat Rev Neurosci 14 673-680. [Crossref]

28. Knowland D, Lilascharoen V, Pacia CP, Shin S, Wang EH, et al. (2017) Distinct ventral pallidal neural populations mediate separate symptoms of depression. Cell 170: $284-297$.

29. Li K, Zhou T, Liao L, Yang Z, Wong C, et al. (2013) $\hat{I}^{2} \mathrm{CaMKII}$ in lateral habenula mediates core symptoms of depression. Science 341: 1016-1020. [Crossref]

30. Zhang Y, Zhao Y, Pan F, Zhang P (2016) EGb761 attenuates depressive-like behaviours induced by long-term light deprivation in C57BL/6J mice through inhibition of NF- $\hat{I}^{\circ} \mathrm{B}-$ IL-6 signalling pathway. Cent Eur J Immunol 41: 350-357. [Crossref]

31. Bai YM, Su TP, Li CT, Tsai SJ, Chen MH, et al. (2015) Comparison of pro-inflammatory cytokines among patients with bipolar disorder and unipolar depression and normal controls. Bipolar disord 17: 269-277. [Crossref]

32. Slavich GM, Irwin MR (2014) From stress to inflammation and major depressive disorder: a social signal transduction theory of depression. Psychol Bull 140: 774-815. [Crossref]

33. Kim JW, Szigethy EM, Melhem NM, Saghafi EM, Brent DA (2014) Inflammatory markers and the pathogenesis of pediatric depression and suicide: a systematic review of the literature. J Clin Psychiatry 75: 1242-1253. [Crossref]

34. Rethorst CD, Toups MS, Greer TL, Nakonezny PA, Carmody TJ, et al. (2013) Proinflammatory cytokines as predictors of antidepressant effects of exercise in major depressive disorder. Mol Psychiatry 18: 1119-1124. [Crossref]

35. Liu Y, Ho RC-M, Mak A (2012) Interleukin (IL)-6, tumour necrosis factor alpha (TNF-a) and soluble interleukin-2 receptors (sIL-2R) are elevated in patients with major depressive disorder: a meta-analysis and meta-regression. J Affect Disord 139: 230-239. [Crossref]

36. Christiansen SL, Bouzinova EV (2017) Clock Genes in Depression. InTechOpen.

37. Ben-Hamo M, Larson TA, Duge LS, Sikkema C, Wilkinson CW, et al. (2017) Circadian forced desynchrony of the master clock leads to phenotypic manifestation of depression in rats. eNeuro 3. [Crossref]

Copyright: (C2017 Lu C. This is an open-access article distributed under the terms of the Creative Commons Attribution License, which permits unrestricted use, distribution, and reproduction in any medium, provided the original author and source are credited. 